\title{
Improved nanostructured diamond adhesion on cemented tungsten carbide with boride interlayers
}

\author{
Jamin M. Johnston ${ }^{\mathrm{a}}$, Paul Baker ${ }^{\mathrm{a}}$, Shane A. Catledge ${ }^{\mathrm{a}, *}$ \\ ${ }^{a}$ Department of Physics, University of Alabama, Birmingham, AL 35294-1170, United States \\ *Corresponding author: \\ Shane A. Catledge \\ 310 Campbell Hall \\ 1300 University Boulevard \\ Birmingham, AL 35294-1170 \\ Phone: (205) 934-3693 \\ E-mail: catledge@uab.edu
}

\begin{abstract}
The application of diamond coatings for strengthening cemented tungsten carbide has been previously attempted, but suffers from delamination. Plasma enhanced chemical vapor deposition boriding improves the strength of cemented carbides by forming $\mathrm{WCoB}, \mathrm{W}_{2} \mathrm{CoB}_{2}$, and/or $\mathrm{CoB}$ phases using controllable diborane stoichiometry; this research exploresthese borides as interlayers for nanostructured diamond coatings. Diamond deposition occurred between 600 ${ }^{\circ} \mathrm{C}$ and $1100{ }^{\circ} \mathrm{C}$ at $100{ }^{\circ} \mathrm{C}$ increments for $30 \mathrm{~min}$ to $4 \mathrm{hrs}$. Raman spectroscopy showed enhanced diamond growth compared to untreated WC-Co,however predominantlyWCoB and CoBphase interlayerssuffered from diamond film delamination. Examination by scanning electron microscopy and energy dispersive X-ray spectroscopy showed interfacial cobalt clusters on these interlayers. Predominantly $\mathrm{W}_{2} \mathrm{CoB}_{2}$ phase interlayers showed improvement with a reduction in reactive cobalt, and improved adhesion of nanostructured diamond coatings. Diamond on $\mathrm{W}_{2} \mathrm{CoB}_{2}$ was well adhered with deposition temperature dependentnanoindentationhardness ranging from 10 to $60 \mathrm{GPaand}$ elastic modulus of 400 to $750 \mathrm{GPa}$. Scratch testing revealed cohesiveand adhesive failure of the diamond coatings at $5 \mathrm{~N} \pm 2 \mathrm{~N}$ and $8 \mathrm{~N} \pm 2 \mathrm{~N}$ respectively and epoxy pull testing resulted in a surface adhesion tensile strength of $8.2 \mathrm{MPa} \pm .1 \mathrm{MPa}$. The $\mathrm{W}_{2} \mathrm{CoB}_{2}$ phaseis shown to be desirable as an interlayer for improved nanostructured diamondadhesion on cemented tungsten carbide.
\end{abstract}

Keywords:WC-Co, boriding, ternary boride, $\mathrm{W}_{2} \mathrm{CoB}_{2}$, nanostructured diamond 


\section{Introduction}

Increasingly robust materials are needed to meet the growing demands of a modern society. Diamond and diamond coatings represent the apex of many material properties to reduce wear and failure of everything from machine parts and mining tools to medical implants and circuit components. Unfortunately, the high strength and hardness that make bulk diamond valuable as an industrial material also make it difficult to implement. As a result, there isan interest in diamond coating technology to improve the surface properties of existing materials that already fill functional niches. However, the process of growing diamond presents its own problems, most notoriously, poor diamond nucleation and adhesion on some metals[1].

One such example is the fabrication of diamond coatings on cemented tungsten carbide (WC-Co). WC-Co is a sintered cermet of tungsten, carbon and cobalt,with traces of oxygen and nitrogen impurities[2]. Tungsten carbide is one of the most widely used materials for industrial mining and drilling operations due to its high strength and hardness. Despite these properties, failure can occur rapidly, leading to wasted time and material. Diamond coatings are an ideal solution to improve this already durable substrate, but direct diamond coating has been problematic [3, 4]. Like many alloys, the presence of transition metals, such as cobalt, are prohibitive to the diamond growth process. These transition metals have high carbon which hinders diamond nucleation, oftenresulting in graphite and undesirable carbon formation that weakens the surface bonding of any subsequent diamond [5-7].Pre-treatment methods, such as two-step acid etching[8], exist to improve diamond adhesion by etching away cobalt from the carbide material. These methods are excellent for improving the quality and adhesion of diamond films; however, etching has been shown to weaken the bulk cemented carbide[9] making this method inappropriate for applications that require an extraordinary strength in the bulk material in addition to a high hardness surface layer. The use of boride interlayers has been investigated as a solution to these pitfalls, and has shown promising results[10-13]. This work considers boride interlayers as an alternative approach rather than a replacement for two-step pretreatment, and is therefore compared to diamond on untreated WC-Co.

Plasma enhanced chemical vapor deposition (PECVD) boriding has previously been used for improved material properties and as a pre-treatment for diamond deposition[12, 14]. The resulting transition metal-boride layer has been shown to be a good candidate for diamond coatings[12, 14-16]. We have shown this to be the case for medical grade cobalt-chromium alloy, which contains a substantially higher percentage of cobalt [17]. Furthermore, preliminary data taken from field tests has shown significant improvement in WC-Co longevity with diamond coating treatment, ranging from $400 \%$ for roof bolt drilling to $12000 \%$ in directional drilling[18].

Although there have been reports of diamond coatings on boride treated tungsten carbide[19], our recent work provides a more detailed examination of the various boride phases formed at different temperatures [20]. This examination of boride phases revealed four possible interlayers with phases consisting primarily of mixed $\mathrm{WCoB} / \mathrm{CoB}$, mixed $\mathrm{W}_{2} \mathrm{CoB}_{2} / \mathrm{WCoB}$, $\mathrm{W}_{2} \mathrm{CoB}_{2}$, and $\mathrm{WCoB}$. These phases have discreet surface chemistry that showed promising qualities for diamond deposition. Specifically, these borides had high hardness, elastic modulus and surface adhesion.In the present study, we take each of these four precursor boride coatings and examine the PECVD diamond growth at a range of temperatures and times to produce a detailed map of diamond coating viability for borided cemented tungsten carbide within a range from $600{ }^{\circ} \mathrm{C}-1100{ }^{\circ} \mathrm{C}$ for times 30 minutes to 4 hours. 


\section{Experimental methods}

\subsection{Sample Preparation}

TM6 grade carbide composed of 94\% WC, 6\% Co binder was used for a substrate and control in all samples. Thesemedium grain carbides had a known hardness of 89.6-90.4 (Ra) and 1500-2000 (Hv)[21]. The carbide bits measured 10mm diameter by $3 \mathrm{~mm}$ height. Samples were polished at $350 \mathrm{rpm}$ for 10 minutes with each of 125, 70, 30, 15 and 9 micron metal-bonded diamond pads, and then polished with diamond solution at 9, 6, 3, and 1 microns for an additional 10 minutes. Polished samples were then cleaned via sonication with acetone and then methanol for 20 minutes each, followed by a deionized water rinse.

\subsection{Boriding and Diamond deposition}

A $2.45 \mathrm{GHz}$ microwave-plasma CVD (Wavemat, Ann Arbor, MI, USA) chamber was utilized. Boriding was performed with a diborane $\left(\mathrm{B}_{2} \mathrm{H}_{6}\right)$ and hydrogen $\left(\mathrm{H}_{2}\right)$ feedgas mixture consisting of $500 \mathrm{sccm}$ of high purity $99.9 \%\left(\mathrm{H}_{2}\right)$ and $3.0 \mathrm{sccm}$ of $\mathrm{B}_{2} \mathrm{H}_{6}$ (provided as a $10 \%$ dilution in $\mathrm{H}_{2}$ ). Boriding parameters were varied in temperature and time as described in our previous work[20]. Mixed phaseWCoB/CoB, mixed phase $\mathrm{W}_{2} \mathrm{CoB}_{2} / \mathrm{WCoB}, \mathrm{W}_{2} \mathrm{CoB}_{2}$, and $\mathrm{WCoB}$ coated samples were fabricated for diamond deposition. The listed borides are each the predominate surface phase, and in the case of mixed $\mathrm{WCoB} / \mathrm{CoB}$ and mixed $\mathrm{W}_{2} \mathrm{CoB}_{2} / \mathrm{WCoB}$ each phase has similar concentration and is a combined predominant phase as determined by XRD analysis. Following boriding, samples were cleaned via sonication with acetone then methanol for 20 minutes each. After cleaning, samples were individually sonicated with a methanol/nanodiamond slurry(International Technology Center, Research Triangle Park, NC, USA) with average diamond particle size of $4 \mathrm{~nm}(0.2 \% \mathrm{w} / \mathrm{v})$ for 30 minutes, followed by a methanol then deionized water rinse.

The same Wavemat system was used for all diamond growth processes. Diamond deposition took place using a hydrogen, methane, and nitrogen feedgas mixture consisting of 500 sccm of high purity $99.9 \%\left(\mathrm{H}_{2}\right), 50 \mathrm{sccm}$ of $\mathrm{CH}_{4}$ and $5.0 \mathrm{sccm}$ of $\mathrm{N}_{2}$. Chamber pressure was fixed at 50 Torr. Mircowave power ranged from .6 to $1.5 \mathrm{~kW}$, but was set at a fixed value for each specific target substrate temperature. Substrate temperature was measured using a two-color optical pyrometer centered at $1.6 \mu \mathrm{m}$. Diamond coatings on borided WC-Co samples were fabricated between $600-1000{ }^{\circ} \mathrm{C}$ at 100-degree intervals using a 30, 60, 90, 120 and 240 minute duration.

\subsection{Characterization}

Diamond film characterization was achieved through a combination of Raman spectroscopy, scanning electron microscopy (SEM), energy dispersive spectroscopy (EDS), nanoindendation hardness, progressive load scratch testing, and epoxy pull adhesion testing.Micro-Raman spectra were collected from the diamond coatings using an argon-ion laser $(\lambda=514.5 \mathrm{~nm})$ at a laser power of $100 \mathrm{~mW}$.A FEI QuantaTM 650 field emission gun with 1.2 $\mathrm{nm}$ spatial resolution was used at $20 \mathrm{kV}$ for both SEM and EDS data collection. SEM was performed in secondary electron mode. Scans were done for the planar surface of the diamond coatings before and after delamination, and for the cross-section of the diamond-boride-carbide to observe change in chemical composition across the interface and from layer to layer.ANanoindenter XP system was used to evaluate hardness at a maximum depth of $400 \mathrm{~nm}$. Material hardness and elastic modulus were examined before boriding on the bare alloy, after boriding and after diamond deposition. 
A Romulus IV (Quad Group Inc., Spokane, WA, USA) progressive load scratch testing system with $200 \mu \mathrm{m}$ radius spherical diamond tip was used to evaluate surface adhesion (ASTM C1624)[22]. The maximum force used was $20 \mathrm{~N}$ with a load rate of $1 \mathrm{~N} / \mathrm{s}$ over a distance of 5 $\mathrm{mm}$. Coating thickness ranged from $3 \mu \mathrm{m}$ to $5 \mu \mathrm{m}$ with an average of $4.2 \mu \mathrm{m} \pm .4 \mu \mathrm{m}$. Scratches were examined by optical microscopy to observe cracking and delamination.An epoxy pull-off test was used to determine surface adhesion using tensile force. In the absence of a discrete standard for pull off tests of thin films, information was used from "Standard Test Method for Pull-Off Strength of Coatings Using Portable Adhesion Testers" ASTM D4541[23] and recommendations from literature [24]. An Instron 1122 system (Instru-met Corporation, Union, NJ, USA) was used. Samples were braced in a steel holder. $3 \mathrm{~mm}$ diameter steel rod was sectioned at 8 inches and polished before being mounted to the samples surfaces with DP805 epoxy (3M Corp., Maplewood, MN). The epoxy was allowed to cure for 24 hours prior to testing. Pull tests were performed at a loading rate of $.1 \mathrm{~mm}$ per min. Loading force data gathered through this test was normalized using the contact area of the steel rod and epoxy.

\section{Results and Discussion}

\subsection{Delamination of diamond films}

Diamond deposition was performed on five discrete sample types. Sample surface phases were established by XRD Rietveld refinement and are listed as a percent phase composition by weight with the remainder being hexagonal WC: a polished control sample of untreated cemented carbide $(6 \% \mathrm{Co})$, a mixed $\mathrm{WCoB}(12 \%) / \mathrm{CoB}(14 \%)$ layer formed at $800{ }^{\circ} \mathrm{C}$, mixed $\mathrm{W}_{2} \mathrm{CoB}_{2}(11 \%) / \mathrm{WCoB}(13 \%)$ formed at $850{ }^{\circ} \mathrm{C}$, primarily $\mathrm{W}_{2} \mathrm{CoB}_{2}(40 \%, 10 \% \mathrm{WCoB}$ remains) formed at $900{ }^{\circ} \mathrm{C}$, and $\mathrm{WCoB}(75 \%)$ formed at $1000{ }^{\circ} \mathrm{C}$. The XRD process, even at low glancing angle, has some penetration depth resulting in an expected heavy presence of WC in the Rietveld refinement. Information regarding the specific crystal structure, phase concentration, and physical properties of these borides was established in our previous work[20]. In every case diamond films were successfully grown on the respective substrate; however, diamond films formed on the polished control sample, mixed $\mathrm{WCoB} / \mathrm{CoB}$ and $\mathrm{WCoB}$ sample types suffered from significant film delamination.

An explanation for the exclusion of $\mathrm{WCoB} / \mathrm{CoB}$ and $\mathrm{WCoB}$ in future tests due to coating delamination is provided here in section 3.1. A total of $n=10$ samples were fabricated for each control sample, mixed $\mathrm{WCoB} / \mathrm{CoB}$ and $\mathrm{WCoB}$ sample types. Film delamination caused from poor surface adhesion and high residual stress occurred in $100 \%$ of cases for these samples. The surfaces of these samples were examined where delamination had occurred to provide insight into the cause of failure. It was found by SEM and EDS that clusters of cobalt were present above the boride layer, as shown in Figure 1. Figure 1A is an SEM scan depicting a cobalt cluster with carbon tube formation; this is confirmed by the EDS spot scan (Figure 1B) that shows reactive cobalt at the interface.

These cobalt clusters are prone to nucleating the growth of carbon fibers, graphite and other undesirable carbon phases[7]. It is believed that the presence of cobalt resulted from the upward thermal diffusion of cobalt from the bulk material during the process for diamond deposition. This cobalt was only seen for the control sample, $\mathrm{WCoB} / \mathrm{CoB}$ and $\mathrm{WCoB}$. For $\mathrm{W}_{2} \mathrm{CoB}_{2} / \mathrm{WCoB}$ and $\mathrm{W}_{2} \mathrm{CoB}_{2}$ surface cobalt was not detected. This is likely due to the higher relative concentration of boron in the interlayer material. This failure to prevent carbon interaction during diamond deposition indicates that $\mathrm{WCoB} / \mathrm{CoB}$ and $\mathrm{WCoB}$ are inadequate interlayers for the diamond deposition process due to the lower concentration of boron when 
compared to $\mathrm{W}_{2} \mathrm{CoB}_{2}$ containing layers. We suggest that during the diamond deposition process, as samples are heated above $600{ }^{\circ} \mathrm{C}$, the $\mathrm{WCoB}$ compounds break down. This allows the migration and interaction of cobalt not just from the bulk but also the WCoB layer. However, the absence of cobalt at the interface after diamond deposition for both $\mathrm{W}_{2} \mathrm{CoB}_{2}$ containing phases suggests that the $\mathrm{W}_{2} \mathrm{CoB}_{2}$ phase does not permit the free diffusion of cobalt. One possible mechanism that would explain the success of $\mathrm{W}_{2} \mathrm{CoB}_{2}$ is the high relative concentration of boron. This may allow for the breakdown of $\mathrm{W}_{2} \mathrm{CoB}_{2}$ to a secondary form that does not allow for free diffusion of cobalt. A reaction such as $\mathrm{Co}($ bulk $)+\mathrm{W}_{2} \mathrm{CoB}_{2}=2 \mathrm{WCoB}$ is proposed. Experiments to confirm this have proven difficult due to the strong adhesion of the diamond coating. Following these results, no further fabrication of $\mathrm{WCoB} / \mathrm{CoB}$ and $\mathrm{WCoB}$ took place. Instead $n=75$ diamond samples were made for each $\mathrm{W}_{2} \mathrm{CoB}_{2}$ and $\mathrm{W}_{2} \mathrm{CoB}_{2} / \mathrm{WCoB}$. The resulting diamond films for these two substrate types were then examined in greater detail.

\subsection{Diamond on WC-Co Boride Layer}

Evidence of diamond growth was confirmed by Raman spectroscopy for all samples. The quality and type of diamond layer formed was independent of the substrate. The Raman spectra for these samples differed based on temperature of deposition and duration of deposition, but was consistent for these temperatures and times regardless of material interlayer. The adhesion of these films varied based on interlayer composition. The Raman spectra shown in Figure 2 were taken using $\mathrm{W}_{2} \mathrm{CoB}_{2}$ as an interlayer material. $\mathrm{n}=75 \mathrm{~W}_{2} \mathrm{CoB}_{2}$ samples were fabricated with $\mathrm{n}=5$ samples for each temperature and time composition. Figure 2 shows the Raman spectra of samples formed at $600{ }^{\circ} \mathrm{C}, 800{ }^{\circ} \mathrm{C}$, and $1000{ }^{\circ} \mathrm{C}$ all for 2 hours. Figure $2 \mathrm{~A}$ shows that for lower temperatures $\left(600{ }^{\circ} \mathrm{C}\right)$ primarily graphitic carbon is formed, this transitions into typicalnanocrystalline diamond at $800{ }^{\circ} \mathrm{C}$ (Figure 2B), and microcrystal diamond structures at $1000{ }^{\circ} \mathrm{C}$ (Figure 2C). The graphitic carbon phase is revealed by characteristically dominant carbon $\mathrm{D}$ and $\mathrm{G}$ bands. At $800{ }^{\circ} \mathrm{C}$ the carbon $\mathrm{D}$ and $\mathrm{G}$ bands are still prominent, but they are joined by a distinctive $\mathrm{SP}_{3}$ diamond peak at $1332 \mathrm{~cm}^{-1}$. For nanocrystalline diamond, this is typically flanked by transpolyacetylenepeaks at $1150 \mathrm{~cm}^{-1}$ and $1480 \mathrm{~cm}^{-1}$, as seen here. At 1000 ${ }^{\circ} \mathrm{C}$ we see a strong sharpening of the diamond peak at $1332 \mathrm{~cm}^{-1}$, this is caused by a combination of higher relative diamond concentration and dehydrogenation from t-PA at this higher temperature.Nanocrystal size for $800^{\circ} \mathrm{Cdiamond}$ was confirmed by SEM in Figure 3.

A SEM surface scan was performed to examine the surface structure of the diamond film. The planar surface scan for diamond coatings formed at $800{ }^{\circ} \mathrm{C}$ reveals a continuous film of nanodiamond grains (Figure 3A). A closer examination (Figure 3B) shows a defined cubic structure and diamond grains of roughly $2-5 \mathrm{~nm}$ size.

\subsection{SEM and EDS of Diamond on WC-Co Boride Layer}

Following confirmation of the presence of diamond by Raman spectroscopy EDS and SEM were performed on the planar surface and cross sectional surface of diamond coated samples.Figure 4 shows samples that have undergone the diamond coating process at $800{ }^{\circ} \mathrm{C}$ after various surface pretreatments; including polished $\mathrm{WC}-\mathrm{Co}$ (A), $\mathrm{W}_{2} \mathrm{CoB}_{2}$ formed at 900 ${ }^{\circ} \mathrm{C}(\mathrm{B})$, and $\mathrm{WCoB}$ formed at $1000{ }^{\circ} \mathrm{C}(\mathrm{C})$. Figure $4 \mathrm{~A}$ does not show the presence of diamond as it was not possible to create a sufficiently well adhered diamond layer for diamond adhesion to persist through epoxy mounting and cross sectioning. Figure 4B is typical for both mixed phase $\mathrm{WCoB} / \mathrm{W}_{2} \mathrm{CoB}_{2}$ formed at $850{ }^{\circ} \mathrm{C}$ and $\mathrm{W}_{2} \mathrm{CoB}_{2}$, so only the case for $\mathrm{W}_{2} \mathrm{CoB}_{2}$ formed at $900{ }^{\circ} \mathrm{C}$ is shown. Figure $4 \mathrm{C}$ shows diamond in the process of delamination on the WCoB phase formed at $1000{ }^{\circ} \mathrm{C}$, but this result is also typical for the mixed phase $\mathrm{CoB} / \mathrm{WCoB}$ formed at $800{ }^{\circ} \mathrm{C}$. 
A typical cross-sectioned image of diamond on borided cemented carbide is shown in Figure 5A. During the SEM scanning process Figure 5A was tuned for contrast to show the boride layer. Nanodiamond crystal grains can be seen in a discrete diamond film atop a boride film on the WC-Co substrate. An EDSlinescan of this sample (Figure 5B) shows an expected high carbon signature in the area of the diamond film. The percentage of carbon quickly decreases through the boride layer. This drop in relative carbon signature corresponds to a simultaneous increase in boron signature around $3 \mu \mathrm{m}$. This indicates that the boron measurement signal is a real indicator of boron in the intermediate layer, rather than a scaled signal due to carbon. The substrate itself has a typical WC-Co signal that begins at $6 \mu \mathrm{m}$ (indicated by the solid line in figure $5 \mathrm{~A}$ and $5 \mathrm{~B}$ ). The substrate is marked by a sharp rise in tungsten concentration, and a decrease in boron and carbon signal. The spike in cobalt at $10 \mu \mathrm{m}$ is caused by a cobalt grain in the cermet structure of WC-Co.

\subsection{Nanoindentation Hardness}

Nanoindentation of diamond films grown on $\mathrm{W}_{2} \mathrm{CoB}_{2}$ and $\mathrm{W}_{2} \mathrm{CoB}_{2} / \mathrm{WCoBwas}$ performed. The results for diamond on these interlayers was the same, therefore only the results for $\mathrm{W}_{2} \mathrm{CoB}_{2}$ are shown. Figure 6 shows the nanoindentation hardness and elastic modulus for a total of $\mathrm{n}=75$ samples of diamond films grown at $600{ }^{\circ} \mathrm{C}, 700{ }^{\circ} \mathrm{C}, 800{ }^{\circ} \mathrm{C}, 900{ }^{\circ} \mathrm{C}$ and $1000{ }^{\circ} \mathrm{C}$. At each temperature $n=5$ samples were fabricated for every time of 30,60, 90, 120 and 240 minutes. Nanoindentation was then performed with a total of $n=25$ indents per sample yielding 125 measurements per data point. $\mathrm{X}$ error bars are a fixed value of $\pm 20{ }^{\circ} \mathrm{C}$ based on measurement difficulty present due the reticle size of the optical pyrometer used to measure temperature. $\mathrm{Y}$ error bars are the result of the standard of deviation at each pointfor $\mathrm{n}=125$ measurements. The deviation in hardness and modulus for these samples at each point is substantial but expected due to surface roughness. Despite the degree of error, a significant trend was observed for both hardness and elastic modulus. The hardness and elastic modulus were shown to increase with deposition temperature. In both cases the hardness and modulus transition from values that are consistent with graphitic carbon $(15 \pm 10$ and $450 \pm 200 \mathrm{GPa})$ at $600{ }^{\circ} \mathrm{C}$ to nanostructured diamond film values $(32 \pm 12$ and $600 \pm 200 \mathrm{GPa})$ at $800{ }^{\circ} \mathrm{C}$ then to microcrystalline hardness and modulus $(60 \pm 10$ and $700 \pm 200)$ at $1000{ }^{\circ} \mathrm{C}$ [25-27]. Previous reported research on nanoindentation hardness and modulus of nanostructured diamond films has varied widely and is heavily dependent on the deposition method[28].

Within the scope of this research, our findings are sufficient to indicate an increase in material surface hardness as deposition temperature is increased. However, an important balance exists between the deposition temperature of the diamond film and the adhesion of the diamond film. In the case of both $\mathrm{W}_{2} \mathrm{CoB}_{2}$ phase containing interlayers delamination due to thermal stress begins to occur at $900{ }^{\circ} \mathrm{C}$. This study suggests that there existsan ideal region of nanostructured diamond hardness between $800{ }^{\circ} \mathrm{C}$ and $900{ }^{\circ} \mathrm{C}$, above which diamond delamination will occur when deposited by PECVD on a polished WC-Co substrate with $\mathrm{W}_{2} \mathrm{CoB}_{2}$ interlayers. This does not imply a correlation between diamond hardness and adhesion; rather that the diamond hardness is influenced by deposition temperature and that increased deposition temperature separately increases the residual thermal stress in the diamond film leading to delamination.

\subsection{Surface Adhesion}

The surface bonding strength or surface adhesion between the diamond film and the boron treated substrate is an important property when considering the applications of this 
diamond treatment. Two methods, progressive load scratch testing and epoxy pull stub testing, were used to evaluate surface adhesion. Our previously reported scratch testing results for only the boride layer on $\mathrm{WC}-\mathrm{Co}$ showed cohesive failure at $37 \mathrm{~N} \pm 3 \mathrm{~N}$ and adhesive failure at $42 \mathrm{~N} \pm$ $5 \mathrm{~N}$ and $65 \mathrm{~N} \pm 7 \mathrm{~N}$ for $\mathrm{W}_{2} \mathrm{CoB}_{2}[20]$. For diamond films in the current study, scratch testing was performed for 5 samples of each $\mathrm{W}_{2} \mathrm{CoB}_{2}$ and $\mathrm{W}_{2} \mathrm{CoB}_{2} / \mathrm{WCoB}$ at each diamond deposition temperatures of $600{ }^{\circ} \mathrm{C}, 800{ }^{\circ} \mathrm{C}$ and $1000{ }^{\circ} \mathrm{C}$ with 5 scratches per sample for a total of $n=25$ tests per temperature and interlayer combination.Coating thickness ranged from $3 \mu \mathrm{m}$ to $5 \mu \mathrm{m}$ with an average thickness ( $\mathrm{n}=5$ per deposition temperature) of $4.2 \mu \mathrm{m} \pm .4 \mu \mathrm{m}$ as determined by SEM. In this study, no significant difference was observed in diamond film thickness due to deposition temperature. This suggests that diamond growth may have been limited by $\mathrm{CH}_{4}$ flow rate. Cohesive and adhesive failure of the diamond films did not significantly differ between the $\mathrm{W}_{2} \mathrm{CoB}_{2} / \mathrm{WCoB}$ and $\mathrm{W}_{2} \mathrm{CoB}_{2}$ interlayers. $\mathrm{W}_{2} \mathrm{CoB}_{2}$ results are reported.Diamond samples prepared at $600{ }^{\circ} \mathrm{Cshowed}$ adhesion failure below the detection limit for the device used in progressive load scratch testing. Cohesive (conformal cracks) and adhesive (gross spallation) failure occurred at $5 \mathrm{~N} \pm 2 \mathrm{~N}$ and $8 \mathrm{~N} \pm 2 \mathrm{~N}$ respectively for diamond prepared at $800{ }^{\circ} \mathrm{C}$. Samples created at $1000{ }^{\circ} \mathrm{C}$ showed no signs of cohesive failure; rather, adhesive (gross spallation) failure occurred at $4 \mathrm{~N} \pm 2 \mathrm{~N}$.An analysis of individual film thickness showed no significant influence on scratch testing critical loads. It is expected that the film thickness may have added to the uncertainty from the scratch testing process, but no trend due to film thickness was observed.Figure 7 shows a typical scratch test result.

Cohesive failure, indicated by the leftmost vertical line (Figure 7A), was determined by optical examination (Figure 7B) and appeared in the form of conformal cracking. Figure 7A has a rise in drag coefficient coupled with a sharp spike in acoustic signal associated with the second vertical line. This is typical of adhesive failure, caused here by gross spallation. The increase in drag coefficient seen at $1.5 \mathrm{~mm}$ is likely due to build-up of debris along the scratch path. These patterns are consistent with a hard film on a hard substrate[22].Residual scratch depth is measured by SEM to be $60 \mu \mathrm{m}$. Gross film delamination propagated well beyond the scratch track in most cases. These results show lower critical loads than have been previously reported at greater than $80 \mathrm{~N}$ for diamond on steel [29] and $60-70 \mathrm{~N}$ on titanium [30], but are consistent with results for diamond grown on ceramic substrates $\mathrm{SiO}_{2}, \mathrm{SiC}, \mathrm{Si}_{3} \mathrm{~N}_{4}$, and $\mathrm{Al}_{2} \mathrm{O}_{3}$ which have failure from $5.8 \mathrm{~N}$ to $13.0 \mathrm{~N}$ [31]. The discrepancy in diamond adhesion is causedby not only the varied substrate but also the diamond deposition methods, nanodiamond structures, diamond coating thickness and scratch testing methods.

Epoxy pull testing was used to determine the resistance of film delamination and tensile adhesion strength. This was used to test the surface adhesion of $\mathrm{W}_{2} \mathrm{CoB}_{2}$ and $\mathrm{W}_{2} \mathrm{CoB}_{2} / \mathrm{WCoB}$ boride films, and diamond films formed at $800{ }^{\circ} \mathrm{C}$ for each boride substrate. Acrylic epoxy DP805 was used for its known adhesive properties and a reported tensile strength of $22 \mathrm{MPa}$. For $\mathrm{n}=5$ tests, including a control sample of polished WC-Co, the epoxy failed before surface delamination at 9.0 $\mathrm{MPa} \pm .3 \mathrm{MPa}$. Thus, boride adhesion for $\mathrm{W}_{2} \mathrm{CoB}_{2}$ and $\mathrm{W}_{2} \mathrm{CoB}_{2} / \mathrm{WCoBwas}$ shown to be greater than 9.0 $\mathrm{MPa} \pm .3 \mathrm{MPa}$. Diamond films, $\mathrm{n}=3$ tests, delaminated from the boride interlayer at $8.2 \mathrm{MPa} \pm .1 \mathrm{MPa}$.For these $\mathrm{n}=3$ tests, diamond film thickness was $4.1 \mu \mathrm{m} \pm$ $.1 \mu \mathrm{m}$. Diamond film thickness is, therefore, not expected to have a significant influence over the epoxy pull test results, but is a possible source of variation for the $8.2 \mathrm{MPa} \pm .1 \mathrm{MPa}$ adhesive measurement.Within the scope of this research, this is considereda sign of good surface adhesion and is considerably improved over control samples that suffer from delamination due to only thermal stress at room temperature. 
When considering the adhesive strength of nanostructured diamond coatings it is also important to consider the effects of residual thermal stress and stress from film thickness. In this paper, section 3.4, it is shown that an increased deposition temperature ultimately resulted in diamond coating delamination. Delamination was observed to occur at room temperature when deposition temperatures of greater than $900{ }^{\circ} \mathrm{C}$ were used. Simultaneously, the use of deposition temperatures below $800{ }^{\circ} \mathrm{C}$ resulted in a poorer quality diamond film with a higher concentration of graphitic carbon. Thus, an evaluation of adhesion at $800{ }^{\circ} \mathrm{C}$ provides insight into improved adhesive properties of a coating with acceptable hardness. For alternate diamond coating processes, where graphitic carbon is not a factor, adhesion is expected to be improved for lower deposition temperatures due to lower residual stress. Nanostructured diamond coating thickness also influences the adhesion of the coating. A thicker coating results in higher residual stress, so a longer deposition time is expected to result in higher residual stress and lower adhesive strength. Conversely a short deposition time or thin coating is expected to have improved adhesion with lower residual stress and the cost of less surface coating material[32]. Ultimately, these properties must be optimized to be application specific.

\section{Conclusion}

The use of microwave enhanced chemical vapor deposition boride pre-treatment on cemented tungsten carbide for diamond deposition is shown to improve the diamond film adhesion for $\mathrm{W}_{2} \mathrm{CoB}_{2}$ interlayers. Diamond adhesion was examined for four pre-established boride interlayers, mixed $\mathrm{WCoB} / \mathrm{CoB}$, mixed $\mathrm{W}_{2} \mathrm{CoB}_{2} / \mathrm{WCoB}, \mathrm{W}_{2} \mathrm{CoB}_{2}$ and $\mathrm{WCoB}[20]$. In every case diamond growth and adhesion was improved when compared to the polished untreated WC-Co substrate. However, interlayers with a low boron to cobalt ratio $(\mathrm{WCoB} / \mathrm{CoB}$ and $\mathrm{WCoB}$ ) still suffered from diamond film delamination due to upward cobalt diffusion and interaction during the diamond deposition process, shown as cobalt and cobalt clusters by SEM and EDS.Deposition between $600{ }^{\circ} \mathrm{C}$ and $700{ }^{\circ} \mathrm{C}$ created films of primarily graphitic carbon, at $700{ }^{\circ} \mathrm{C}$ to $900{ }^{\circ} \mathrm{C}$ a nanostructured diamond film was formed, and from $900{ }^{\circ} \mathrm{C}$ to $1000{ }^{\circ} \mathrm{C}$ microcrystalline diamond was present. Although the $\mathrm{W}_{2} \mathrm{CoB}_{2}$ layers improved diamond adhesion in general, this improvement was not sufficient to overcome thermal stress for the higher temperature microcrystalline case; delamination was observed in diamond layers formed from 900 to $1000{ }^{\circ} \mathrm{C}$. This is likely due simply to high thermal stress from mismatched coefficients of thermal expansion $\left(5.1 \times 10^{-6} \mathrm{k}^{-1}\right.$ for $\mathrm{WC}-\mathrm{Co}$ and $1.0 \times 10^{-6} \mathrm{k}^{-1}$ for diamond) and the thicker diamond coating formed at these temperatures.

EDS scans of cross-sectioned samples showed diamond growth on a discrete boride layer atop bulk WC-Co. This indicates that the boride interlayer is not lost during the diamond deposition process. Nanoindentation testing for diamond film hardness and elastic modulus showed an increase as deposition temperature was increased. At lower temperatures $\left(600{ }^{\circ} \mathrm{C}\right)$ graphitic carbon was formed with a resulting hardness of $15 \pm 10 \mathrm{GPa}$ and elastic modulus of 400 $\pm 200 \mathrm{GPa}$. Nanostructured diamond formed at $800^{\circ} \mathrm{C}$ had a hardness and elastic modulus of 32 $\pm 12 \mathrm{GPa}$ and $600 \pm 200 \mathrm{GPa}$ respectively. At $1000{ }^{\circ} \mathrm{C}$, microcrystalline hardness and modulus were observed to be $60 \pm 10 \mathrm{GPa}$ and $700 \pm 200 \mathrm{GPa}$. Adhesion of the diamond films was examined by progressive loadscratch testing and anepoxy stud-pull test. Scratch testing resulted in cohesive failure at $5 \pm 2 \mathrm{~N}$ and adhesive failure at $8 \mathrm{~N} \pm 2 \mathrm{~N}$ for diamond films formed on mixed $\mathrm{W}_{2} \mathrm{CoB}_{2} / \mathrm{WCoB}$ and $\mathrm{W}_{2} \mathrm{CoB}_{2}$. Theepoxy stud pull test provideda tensile adhesion result of8.2 $\mathrm{MPa} \pm .1 \mathrm{MPa}$ for diamond coatings on $\mathrm{W}_{2} \mathrm{CoB}_{2}$ and mixed phase $\mathrm{W}_{2} \mathrm{CoB}_{2} / \mathrm{WCoB}$ interlayers. 
The PECVD diamond films deposited on $\mathrm{W}_{2} \mathrm{CoB}_{2}$ show improved diamond film adhesion that could be appropriate for low friction coating applications. However, the inability to maintain diamond adhesion for the harder microcrystalline diamond phase suggest that this process may not be applicable for extreme conditions such as hard rock drilling where sheer stresses will be high. Furthermore the nanostructured diamond film properties $(32 \pm 12 \mathrm{GPa}$ and $600 \pm 200 \mathrm{GPa}$ ) are not substantially improved over the $\mathrm{W}_{2} \mathrm{CoB}_{2}$ interlayer boride properties previously reported $(29 \pm 2 \mathrm{GPa}$ and $760 \pm 20 \mathrm{GPa})[20]$. Further study into the surface roughness prior to diamond deposition is of interest due to field trial observations. We suggest that a substantial mechanical interlocking effect and increased surface area provided by rough samples could lead to better diamond adhesion.

\section{Acknowledgments}

Our research results are based upon work supported by the National Science Foundation Partnerships for Innovation: Building Innovation Capacity (PFI: BIC) subprogram under Grant No. IIP-1317210. Any opinions, findings, and conclusions or recommendations expressed in this material are those of the author(s) and do not necessarily reflect the views of the National Science Foundation. 


\section{LIST OF CAPTIONS}

Figure 1: Scanning electron microscopy and energy dispersive spectroscopy of diamond-boride interface on WC-Co.(a)False color SEM scan of backscattered electrons (blue) and secondary emission (yellow) shows carbon and carbon tube structure beneath the delaminated diamond film. (b) An EDS spot scan of shows cobalt that was not present at the surface prior to diamond deposition.

Figure 2: Raman spectra of diamond films prepared for 1 hour at $600{ }^{\circ} \mathrm{C}, 800{ }^{\circ} \mathrm{C}$ and $1000{ }^{\circ} \mathrm{C}$. (a) Films grown at $600{ }^{\circ} \mathrm{C}$ consist of primarily graphitic carbon with typical D and $\mathrm{G}$ bands at $1350 \mathrm{~cm}^{-1}$ and $1550 \mathrm{~cm}^{-1}$. (b) Nanodiamond was grown at $800{ }^{\circ} \mathrm{C}$, indicated by characteristic t-PA peaks at $1150 \mathrm{~cm}^{-1}$ and $1480 \mathrm{~cm}^{-1}$, and a diamond peak at $1332 \mathrm{~cm}^{-1}$. (c) At $1000{ }^{\circ} \mathrm{C}$ the Raman spectra continues to show diamond and t-Pa peaks but with a significantly more defined diamond peak at $1332 \mathrm{~cm}^{-1}$.

Figure 3: Scanning electron scan of diamond film on borided WC-Co. (a)A planar surface scan of a diamond film grown at $800{ }^{\circ} \mathrm{C}$ shows nanocrystal diamond grains with cubic crystal orientation. (b) A magnified image of the same film shows a more detailed view of cubic orientation.

Figure 4: Cross-sectional SEM of diamond film on WC-Co with various interlayers. In all cases diamond was grown at $800{ }^{\circ} \mathrm{C}$. (A) Polished, un-borided WC-Co was not able to retain diamond coating through the SEM preparation, so the surface is show bare.(B) Diamond films were well adhered for both mixed phase $\mathrm{WCoB} / \mathrm{W}_{2} \mathrm{CoB}_{2}$, and $\mathrm{W}_{2} \mathrm{CoB}_{2}$ (shown). Here the diamond layer is shown in false color and the boride layer is a faint $3 \mu \mathrm{m}$ region at the interface between the diamond and WC-Co. (C) Diamond films suffered significant delamination for $\mathrm{CoB} / \mathrm{WCoB}$ and $\mathrm{WCoB}$ phases, however some level of adhesion made images of a delaminating diamond coating possible.

Figure 4: Scanning electron microscopy and energy dispersive spectroscopy of diamond on boride on WC-Co. (a) The cross-section SEM image shows a nanocrystal diamond top film atop a $5 \mu \mathrm{m}$ $\mathrm{W}_{2} \mathrm{CoB}_{2}$ coating on bulk WC-Co. (b) An EDS line scan of the cross-sectioned, diamond on borided WC$\mathrm{Co}$, corresponds to the dashed red line on Figure 5a. High carbon concentration is seen in the diamond layer at the start of the linescan that decreases in relative concentration towards the bulk. Tungsten and cobalt are present primarily in the bulk with decreasing concentration toward the surface layer and throughout the boride interlayer; spikes in cobalt signal correspond to discrete cobalt grains. Boron has an increased presence where expected in the boride interlayer and drops off as a diffusion layer at the interface of the bulk, indicated with a solid black line.

Figure 5: Nanoindenation hardness and modulus vs diamond deposition temperature on $\mathbf{W}_{2} \mathrm{CoB}_{2}$. Each data point is an average of $n=125$ measurements taken across $n=5$ samples, $Y$ error bars are the result of the standard of deviation for each point. $\mathrm{X}$ error bars are $\pm 20{ }^{\circ} \mathrm{C}$ based on uncertainty in temperature during deposition. The hardness (A) and modulus (B) transition from values that are consistent with graphitic carbon $(15 \pm 10$ and $450 \pm 200 \mathrm{GPa})$ at $600{ }^{\circ} \mathrm{C}$ to nanostructured diamond film values $(32 \pm 12$ and $600 \pm 200 \mathrm{GPa})$ at $800{ }^{\circ} \mathrm{C}$ then to microcrystalline levels $(60 \pm 10$ and $700 \pm 200)$ at $1000{ }^{\circ} \mathrm{C}$. The left most shaded region on each graph corresponds to the temperature range at which graphitic carbon was formed. The right most shaded region on each graph designates the temperature range at which surface coating delamination occurred at room temperature. 
Figure 6: Progressive load scratch testing of diamond films on borided WC-Co. (a) Progressive load scratch testing for adhesion is shown with the corresponding scratch showing normal load (solid line), drag coefficient (dotted line), and acoustic signal (dashed line). The acoustic signal has been scaled to fit with arbitrary units. Transverse load and normal force are represented by the left Y-axis. Cohesive failure is observed at $5 \mathrm{~N}$ by comparison to optical images. At $8 \mathrm{~N}$, adhesive failure is indicated by a rise in acoustic signal. (b) Cohesive failure, shown by optical microscopy, resulted in cracking of the boride layer along the scratch edges followed buckling spallation indicative of adhesive failure of a hard film on a hard substrate. The residual scratch depth is determined to be $60 \mu \mathrm{m}$.

\section{References}

[1] N. Toprani, S.A. Catledge, Y.K. Vohra, R. Thompson, Interfacial adhesion and toughness of nanostructured diamond coatings, Journal of Materials Research, 15 (2000) 1052-1055.

[2] Z.Z. Fang, X. Wang, T. Ryu, K.S. Hwang, H. Sohn, Synthesis, sintering, and mechanical properties of nanocrystalline cemented tungsten carbide-a review, International Journal of Refractory Metals and Hard Materials, 27 (2009) 288-299.

[3] I. Campos-Silva, D. Bravo-Bárcenas, A. Meneses-Amador, M. Ortiz-Dominguez, H. Cimenoglu, U. Figueroa-López, J. Andraca-Adame, Growth kinetics and mechanical properties of boride layers formed at the surface of the ASTM F-75 biomedical alloy, Surface and Coatings Technology, 237 (2013) 402-414.

[4] P.W. May, Diamond thin films: a 21st-century material, Philosophical Transactions of the Royal Society of London. Series A: Mathematical, Physical and Engineering Sciences, 358 (2000) 473-495.

[5] A. Lettington, J.W. Steeds, Thin Film Diamond, Chapman and Hall, London, New York, 1994.

[6] R.F. Davis, Diamond Films and Coatings, Noyes Publications, New Jersey, 1993.

[7] X. Chen, J. Narayan, Effect of the chemical nature of transition-metal substrates on chemical-vapor deposition of diamond, Journal of Applied Physics, 74 (1993) 4168-4173.

[8] J. Miao, J. Song, Y. Xue, Y. Tong, W. Tang, F. Lu, Effect of a two-step pretreatment method on adhesion of CVD diamond coatings on cemented carbide substrates, Surface and Coatings Technology, 187 (2004) 33-36.

[9] C. Geng, W. Tang, L. Hei, S. Liu, F. Lu, Fracture strength of two-step pretreated and diamond coated cemented carbide microdrills, International Journal of Refractory Metals and Hard Materials, 25 (2007) 159-165.

[10] I. Campos-Silva, The boriding process: growth kinetics and mechanical characterization of boride layers, International Iron \& Steel Symposium, Karabük, Türkiye, 2012, pp. 27-35.

[11] U. Sen, S. Sen, The fracture toughness of borides formed on boronized cold work tool steels, Materials Characterization, 50 (2003) 261-267.

[12] W. Tang, Q. Wang, S. Wang, F. Lu, A comparison in performance of diamond coated cemented carbide cutting tools with and without a boride interlayer, Surface and Coatings Technology, 153 (2002) 298-303.

[13] J.G. Buijnsters, P. Shankar, P. Gopalakrishnan, W.J.P. van Enckevort, J.J. Schermer, S.S. Ramakrishnan, J.J. ter Meulen, Diffusion-modified boride interlayers for chemical vapour deposition of low-residual-stress diamond films on steel substrates, Thin Solid Films, 426 (2003) 85-93.

[14] W. Tang, S. Wang, F. Lu, Preparation and performance of diamond coatings on cemented carbide inserts with cobalt boride interlayers, Diamond and Related Materials, 9 (2000) 1744-1748. 
[15] Q.-p. Wei, Z.M. Yu, M.N.R. Ashfold, J. Ye, L. Ma, Synthesis of micro- or nano-crystalline diamond films on WC-Co substrates with various pretreatments by hot filament chemical vapor deposition, Applied Surface Science, 256 (2003) 4357-4364.

[16] E.R. Kupp, W.R. Drawl, K.E. Spear, Interlayers for diamond-coated cutting tools, Surface and Coatings Technology, 68-69 (1994) 378-383.

[17] J.M. Johnston, M. Jubinsky, S.A. Catledge, Plasma boriding of a cobalt-chromium alloy as an interlayer for nanostructured diamond growth, Applied Surface Science, 328 (2015) 133-139.

[18] J.M. Johnston, S.A. Catledge, Internal Report: field test results for boride pre-treated nanostructured diamond coated TM6 WC-Co 2014.

[19] F. Sun, Z. Zhang, M. Chen, H. Shen, Improvement of adhesive strength and surface roughness of diamond films on Co-cemented tungsten carbide tools, Diamond and Related Materials, 12 (2003) 711718.

[20] J.M. Johnston, S.A. Catledge, Metal-boride phase formation on tungsten carbide (WC-Co) during microwave plasma chemical vapor deposition, Applied Surface Science, 364 (2016) 315-321.

[21] Sandvik Group, Understanding Cemented Carbide, 2015.

[22] S.T. Gonczy, N. Randall, An ASTM standard for quantitative scratch adhesion testing of thin, hard ceramic coatings, International Journal of Applied Ceramic Technology, 2 (2005) 422-428.

[23] Standard Test Method for Pull-Off Strength of Coatings Using Portable Adhesion Testers, 2005.

[24] T.R. Hull, J.S. Colligon, A.E. Hill, Measurement of thin film adhesion, Vacuum, 37 (1987) 327-330.

[25] I. Yanchuk, M.Y. Valakh, A.Y. Vul, V. Golubev, S. Grudinkin, N. Feoktistov, A. Richter, B. Wolf, Raman scattering, AFM and nanoindentation characterisation of diamond films obtained by hot filament CVD, Diamond and related materials, 13 (2004) 266-269.

[26] T.H. Zhang, Y. Huan, Nanoindentation and nanoscratch behaviors of DLC coatings on different steel substrates, Composites Science and Technology, 65 (2005) 1409-1413.

[27] J. López, F.J. Gordillo-Vázquez, J. Albella, Nanocrystalline diamond thin films deposited by 35 kHz Arrich plasmas, Applied surface science, 185 (2002) 321-325.

[28] C.A. Charitidis, Nanomechanical and nanotribological properties of carbon-based thin films: A review, International Journal of Refractory Metals and Hard Materials, 28 (2010) 51-70.

[29] J.G. Buijnsters, P. Shankar, W.J.P. van Enckevort, J.J. Schermer, J.J. ter Meulen, The adhesion of hotfilament CVD diamond films on AISI type 316 austenitic stainless steel, Diamond and Related Materials, 13 (2004) 848-857.

[30] E. Buccioni, E. Braca, J.M. Kenny, M.L. Terranova, Processing-structure-adhesion relationship in CVD diamond films on titanium substrates, Diamond and Related Materials, 8 (1999) 17-24.

[31] M.-G. Jung, J.-H. Kim, S.-K. Lee, Y.-S. Oh, D.-S. Lim, Adhesion of nanodiamond seeded CVD diamond on ceramic substrate, Journal of the Ceramic Society of Japan, 117 (2009) 650-653.

[32] A. Erdemir, C. Donnet, Tribology of diamond-like carbon films: recent progress and future prospects, Journal of Physics D: Applied Physics, 39 (2006). 


\section{Figure 1}

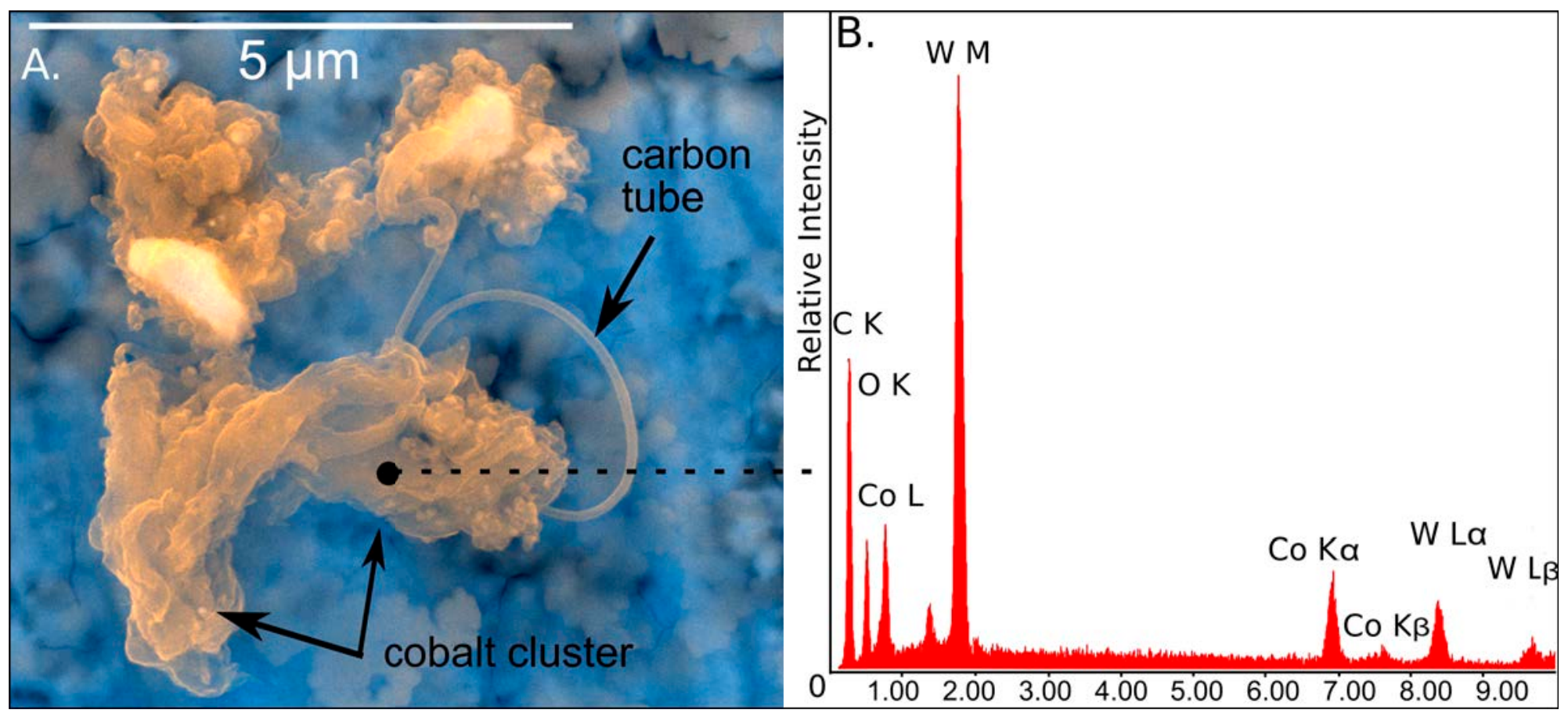




\section{Figure 2}

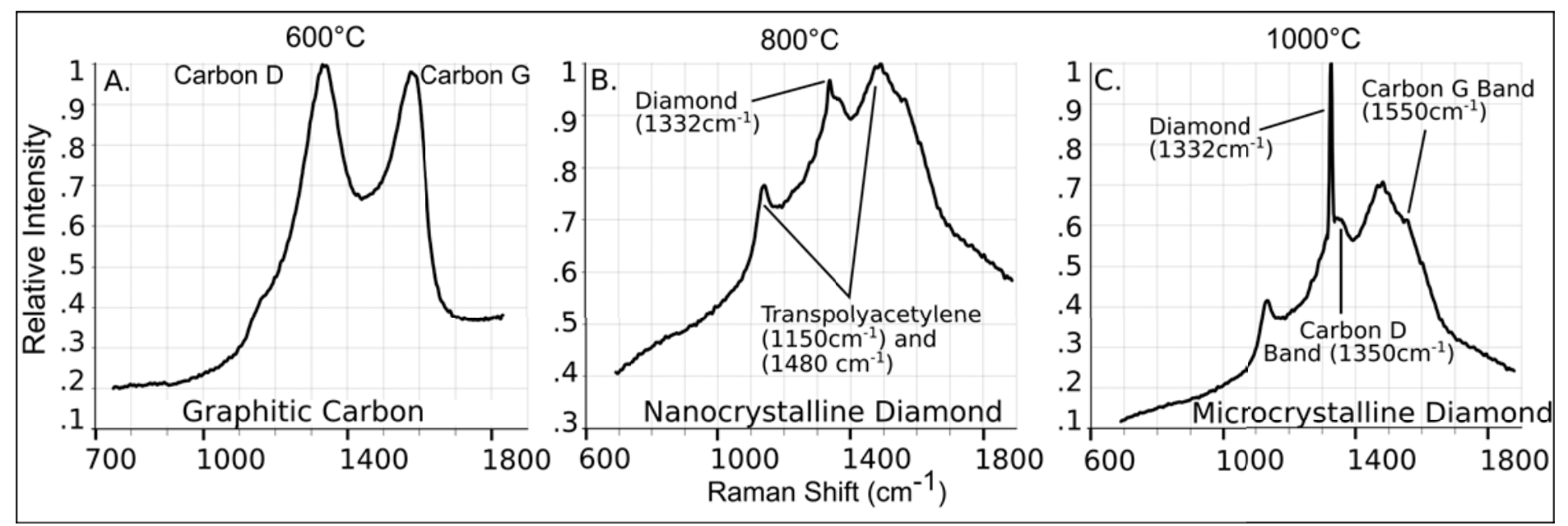


Figure 3

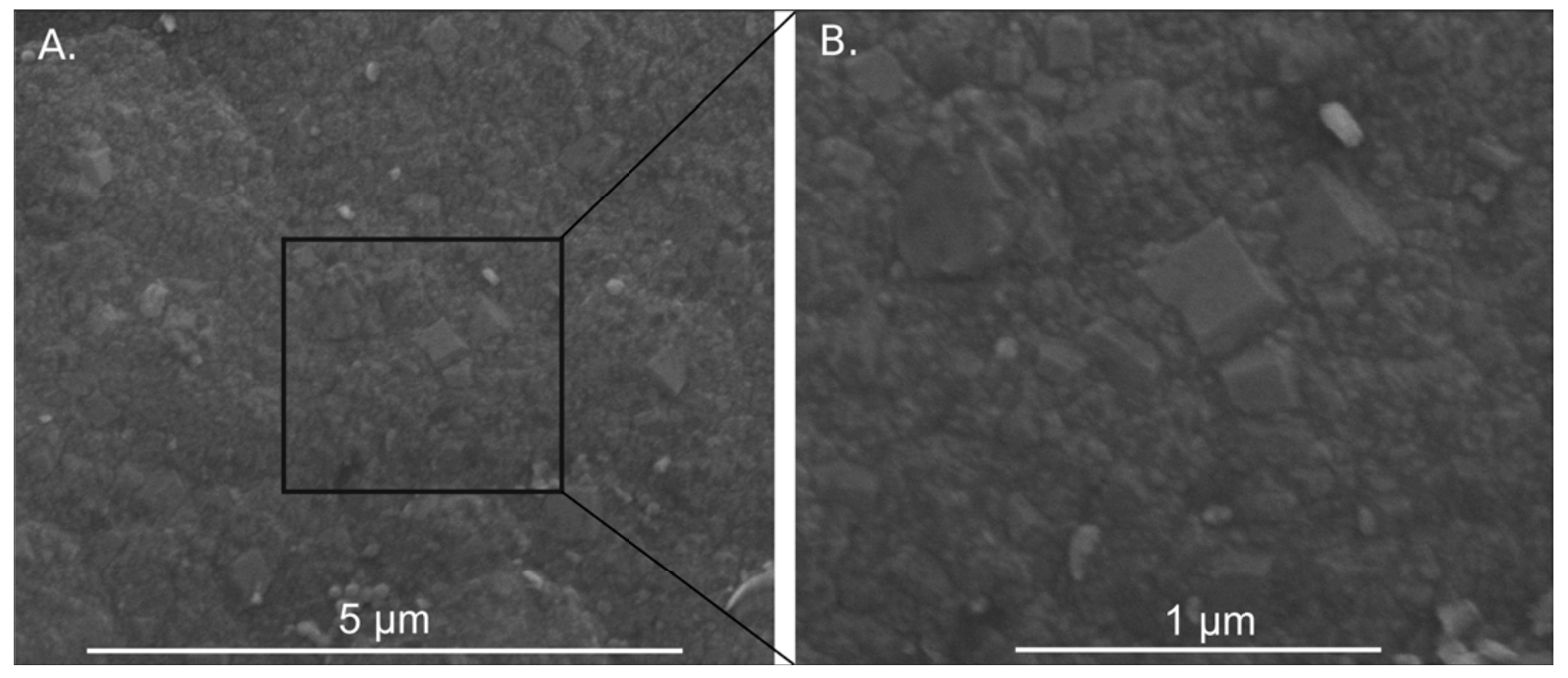




\section{Figure 4}

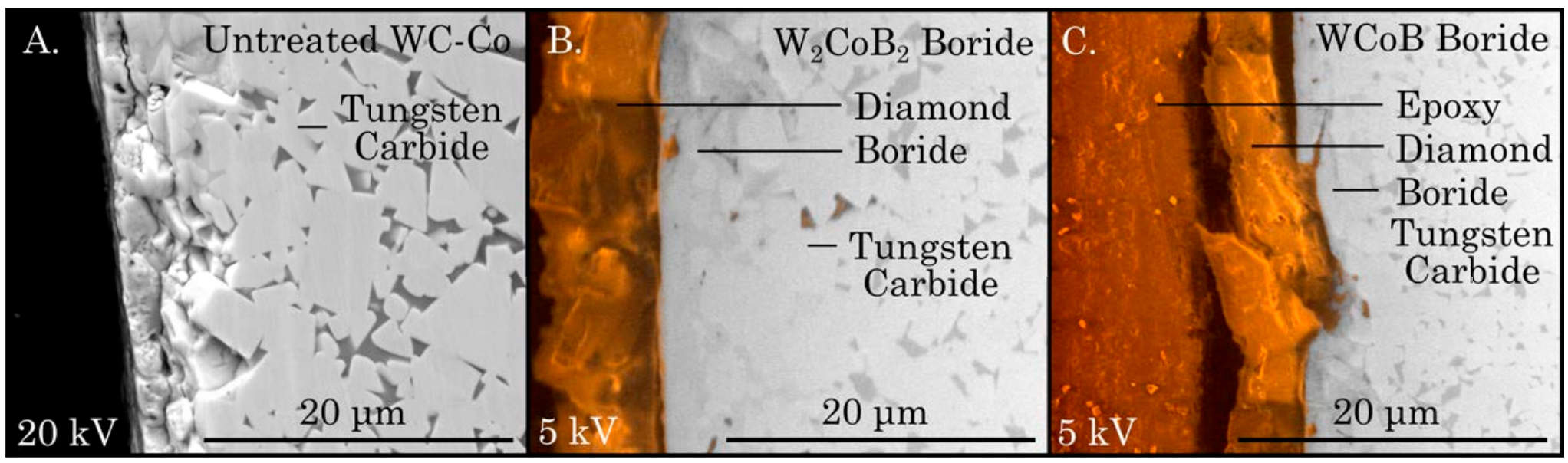


Figure 5

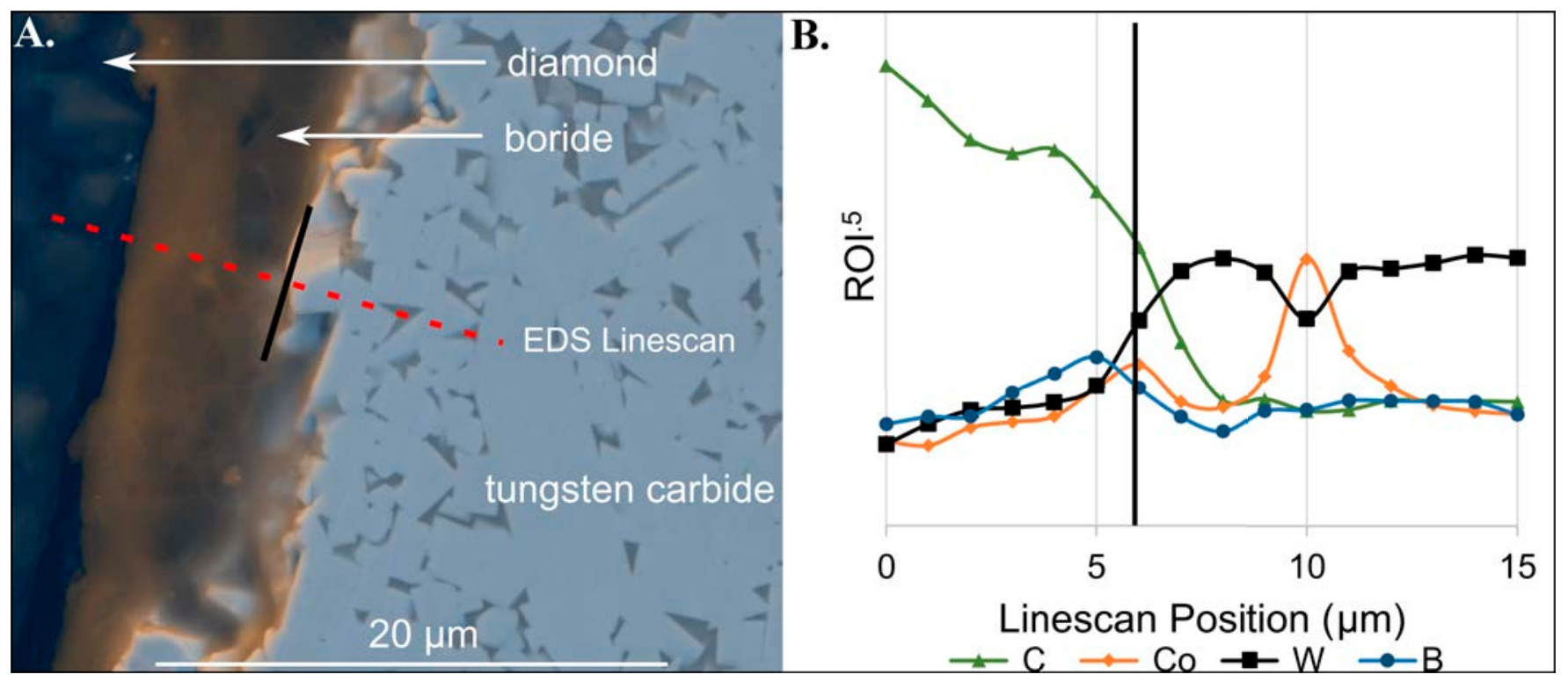




\section{Figure 6}

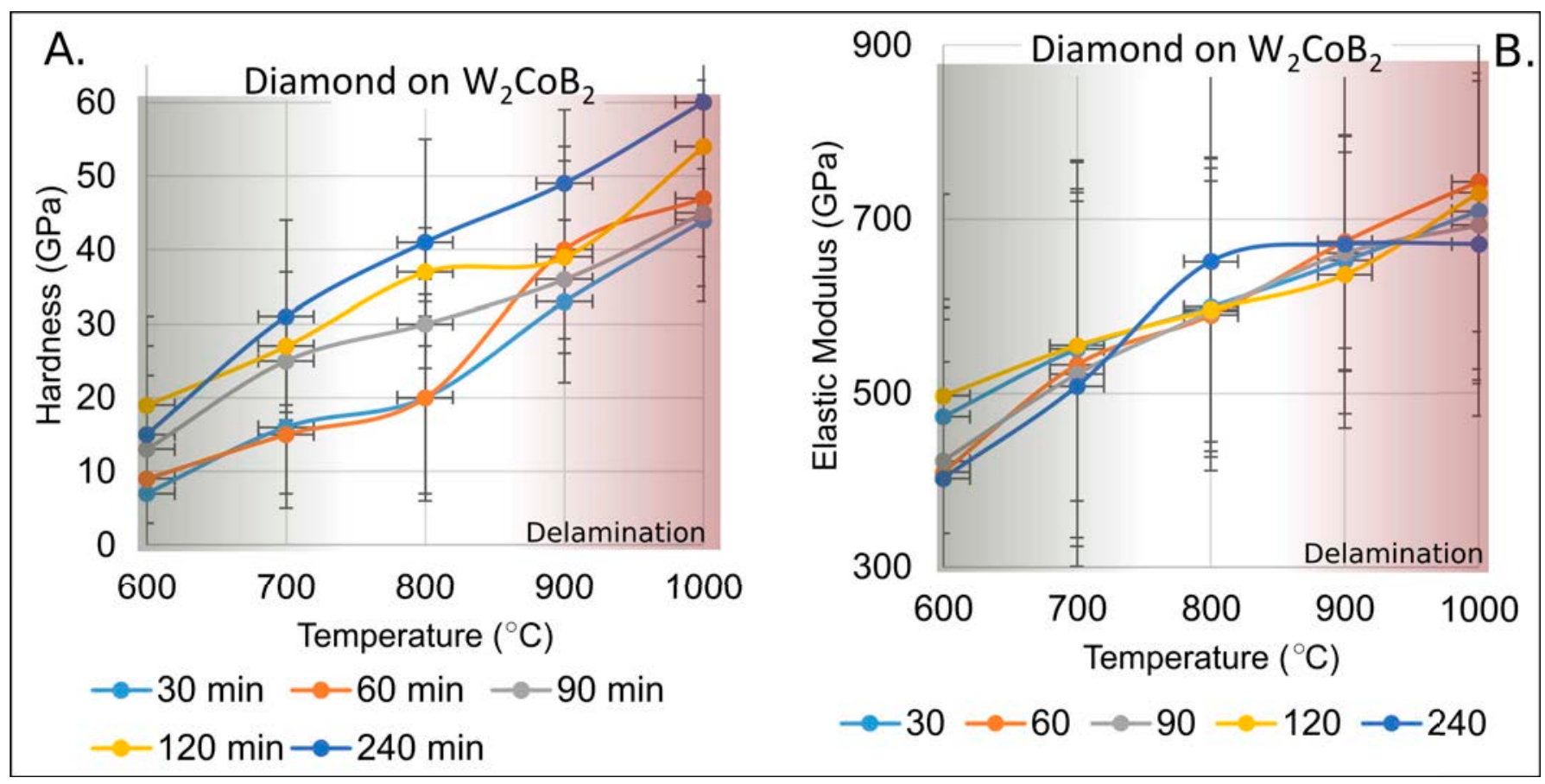




\section{Figure 7}

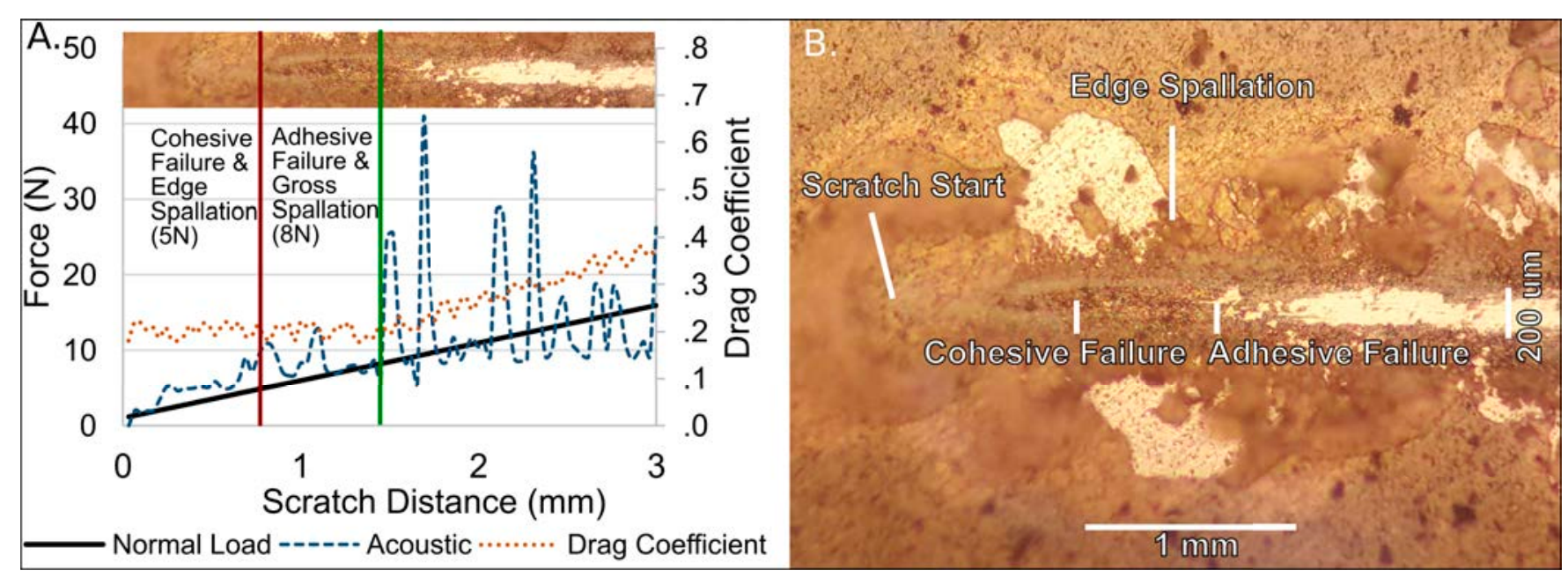




\section{Graphical Abstract}

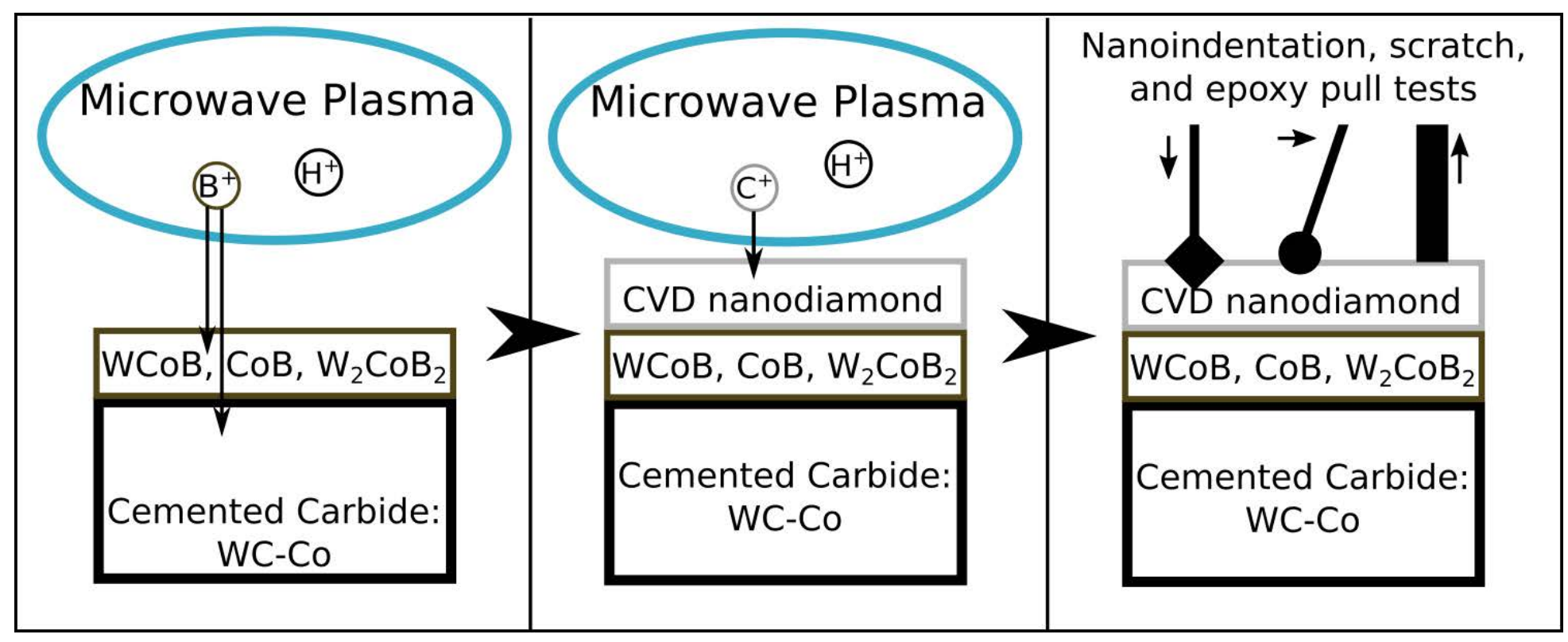

